\title{
Characterization of the Pseudomonas aeruginosa Alginate (alg) Gene Region II
}

\author{
By SHANG-KWEI WANG, ISABEL SA'-CORREIA, $\dagger$ ALDIS DARZINS \\ AND A. M. CHAKRABARTY* \\ Department of Microbiology and Immunology, Unicersity of Illinois Health Sciences Center, \\ Chicago, Illinois 60612, USA
}

(Receited 8 January 1987; retised 24 March 1987)

\begin{abstract}
Pseudomonas aeruginosa region II alginate genes are involved in the biosynthesis of the uronic acid containing exopolysaccharide, alginic acid. We have subcloned and overexpressed various DNA fragments contained within region II in an attempt to further characterize and more precisely localize the genes involved in alginate production. Overexpression of the genes controlling alginate biosynthesis within region II was accomplished by placing various cloned restriction fragments under the transcriptional control of the hybrid trp-lac (tac) promoter, and plasmid encoded proteins were examined in a maxicell expression system. We correlated various region II plasmid constructions with the ability to complement specific alginate negative $(\mathrm{alg})$ mutants and code for polypeptides. Several proteins suspected of being involved in alginate production were encoded by sequences within region II. The results of this study further reveal that the transcriptional orientation of the alg loci within region II appears to be in the direction from $\arg F$ to pmi. The specific activities of phosphomannomutase (PMM) and GDP-mannose pyrophosphorylase (GMP), two enzymes involved in the formation of the alginate precursor GDP-mannuronic acid, were measured in region II alg mutants and in cells overexpressing cloned segments from region II. Based on these enzyme measurements, we conclude that the remaining region II alg genes do not encode either PMM or GMP. These results support the suggestion that the remaining alg genes in region II are likely to be involved in post GDP-mannuronic acid processing events such as mannuronic acid transport, polymerization, secretion, epimerization and acetylation.
\end{abstract}

\section{INTRODUCTION}

Mucoid strains of Pseudomonas aeruginosa isolated from the sputa of cystic fibrosis (CF) patients secrete copious amounts of an exopolysaccharide known as alginic acid (Evans \& Linker, 1973: Mian et al., 1978). These strains are recognized by the gross morphologic aspects of the colonies, which have a raised, highly refractile and confluent appearance on agar solidified media. This mucoid phenotype is thought to represent the transformation of the typical $P$. aeruginosa into an encapsulated variant (Doggett et al., 1971). These mucoid variants are rarely, however, found in non-CF infections despite prolonged colonization in several sites (Doggett, 1979: Iacocca et al. 1963). The exopolysaccharide conferring the mucoid phenotype

† Permanent address: Laboratorio de Engenharia Bioquimica, Instituto Superior Tecnico, 1096 Lisboa Codex, Portugal.

$\ddagger$ Present address: Department of Molecular Genetics and Cell Biology, The University of Chicago, Chicago, Illinois 60637, USA.

Abbreviations: PMI, phosphomannose isomerase; PMM, phosphomannose mutase; GMP, GDP-mannose pyrophosphorylase; GMD, GDP-mannose dehydrogenase: CF, cystic fibrosis; PIA, Pseudomonas Isolation Agar; IPTG, isopropyl $\beta$-D-thiogalactopyranoside. 


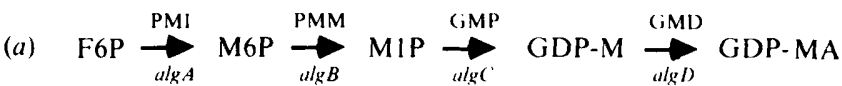

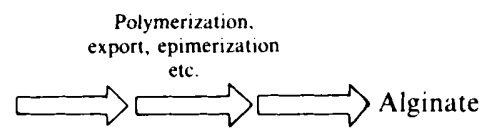

(b)
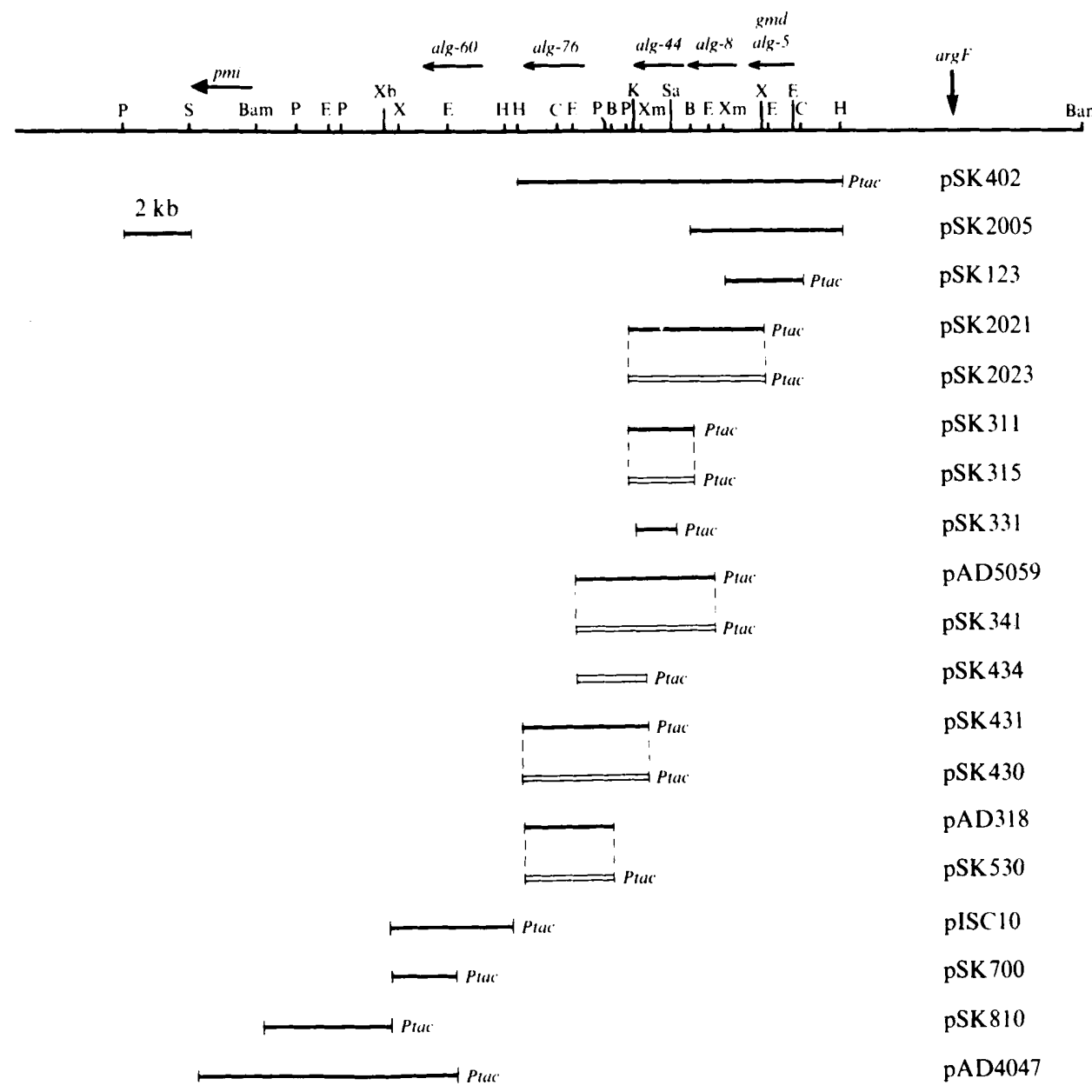

pSK 402

pSK2005

pSK 123

pSK 2021

pSK 2023

pSK 311

pSK 315

pSK 331

pAD5059

pSK 341

pSK 434

pSK 431

pSK 430

pAD318

pSK 530

pISC 10

pSK 700

pSK810

pAD4047

Fig. 1. (a) Alginic acid biosynthetic pathway. F6P, fructose 6-phosphate; M6P, mannose 6-phosphate; M1P, mannose 1-phosphate; GDP-M, GDP-mannose; GDP-MA, GDP-mannuronic acid. (b) Genetic map of region II. The line at the top represents chromosomal DNA sequences from alg region II. The lines below the genetic map represent region II subclones in either pCP13 (solid rectangles), pMMB22 or pMMB24 (solid rectangles with Ptac) or pK K223-3 (open rectangles). Ptac, hybrid trp-lac promoter; B, BglII; Bam, BamHI; C, ClaI; E, EcoRI; H, HindIII; K, KpnI; P, PstI; S, SstI; Sa, SalI; X, XhoI ; $\mathrm{Xb}, \mathrm{XbaI} ; \mathrm{Xm}, \mathrm{XmaI}$.

on these morphological variants is composed of selectively acetylated $\beta$-1,4-linked Dmannuronic acid and its C5 epimer L-guluronic acid (Linker \& Jones, 1966). This polysaccharide is similar to the extracellular polymer which is produced by Azotobacter vinelandii (Gorin \& Spencer, 1966) and certain species of brown algae (Drummond et al., 1962).

Based on the pathway proposed by Lin \& Hassid (1966), a pathway for alginate biosynthesis has been suggested to operate in P. aeruginosa (Piggott et al., 1981; Sutherland, 1982). The 
glycolytic intermediate fructose 6-phosphate is first converted to mannose 6-phosphate and then to mannose 1-phosphate by the action of the enzymes phosphomannose isomerase (PMI; EC 5.3.1.8) and phosphomannose mutase (PMM; EC 5.4.2.8), respectively (Fig. $1 a$ ). The next step involves the formation of guanosine-5'-diphosphomannose (GDP-mannose) from mannose 1-phosphate by GDP-mannose pyrophosphorylase (GMP: EC 2.7.7.13). GDPmannose is then oxidized by GDP-mannose dehydrogenase (GMD; EC 1.1.1.132) to GDPmannuronic acid, and alginic acid is then formed after polymerization of the mannuronic acid residues, epimerization of selected mannuronic acid residues to guluronic acid, and acetylation.

There are several genes, the function of which are essential for producing alginic acid in $P$. aeruginosa. These genes are positioned on the $P$. aeruginos $a$ chromosome in at least two main regions. Region $I$ is located at $19 \mathrm{~min}$ and has been postulated to contain an alginate regulatory element (Darzins \& Chakrabarty, 1984). In addition, DNA within this region has recently been shown to be capable of undergoing amplification resulting in the establishment of the mucoid phenotype, and also to be capable of activating a promoter that controls the expression of the GDP-mannose dehydrogenase gene (Deretic et al., 1986, 1987 b). Region II has been mapped at 45 min of the $P$. aeruginosa PAO chromosome and contains a tight clustering of several genetic loci involved in alginate biosynthesis (Darzins et al., 1985b). This region (Fig. $1 b$ ) has been shown to contain the phosphomannose isomerase ( $p m i)$ and GDP-mannose dehydrogenase ( $g m d)$ genes, whose products catalyse the first and last steps, respectively, in the production of GDP-mannuronic acid from fructose 6-phosphate (Darzins et al., 1985a; Gill et al., 1986; Deretic et al., 1987a). In addition, the nucleotide sequence of the $P$. aeruginosa pmi gene as well as overexpression and identification of the gene product have recently been reported (Darzins $e t$ al., 1986; Gill et al., 1986).

The function of the remaining region II alginate genes, however, is largely unknown, except that they are important in the biosynthesis of alginic acid, since mutations in such genes render the cells phenotypically $\mathrm{Alg}^{-}$. In order to begin to understand the functional organization of the genes involved in the synthesis of this polysaccharide, we have characterized the gene products of region II by overexpressing the alginate genes using strong promoters.

\section{METHODS}

Bacterial strains, plasmids and grow't conditions. The bacterial strains and plasmids used in this study are listed in Table 1. The alg mutants used in this study for genetic complementation were obtained by chemical mutagenesis of the stable mucoid strain 8830 and were described by Darzins \& Chakrabarty (1984). P. aeruginosa strains were routinely grown on Pseudomonas Isolation Agar (PIA) plates (Difco) or in Luria broth (LB) liquid medium (Miller, 1972). Antibiotic concentrations used for maintaining plasmids in $P$. aeruginosa were $50 \mu \mathrm{g}$ tetracycline $\mathrm{ml}^{-1}$ and $300 \mu \mathrm{g}$ carbenicillin $\mathrm{ml}^{-1}$ (for growth on LB liquid medium) and $400 \mu \mathrm{g}$ tetracycline $\mathrm{ml}^{-1}$ and I mg carbenicillin $\mathrm{ml}^{-1}$ (for growth on PIA plates). M9 minimal medium used for cultivating Escherichia coli was described by Miller (1972).

Manipulation of recombinant DNA. Plasmid DNA was isolated using a modification (Chatterjee et al., 1981) of the method described by Casse $e t$ al. (1979). Restriction endonucleases and T4 DNA ligase were purchased from New England Biolabs and were used according to the manufacturers specifications. Calf intestine alkaline phosphatase, linker DNA and T4 infected $E$. coli polynucleotide kinase were obtained from Boehringer Mannheim. For end-labelling $\left[\gamma^{3}{ }^{3:} \mathrm{P}\right] \mathrm{ATP}$ was purchased from Amersham. Routine DNA manipulation, agarose gel electrophoresis and DNA end-labelling were done as described by Maniatis et al. (1982).

Genetic analysis of alginate biosynthetic genes. Triparental matings were done as described by Figurski \& Helinski (1979) by using pRK2013 as a helper plasmid to mobilize recombinant plasmids from E. coli to P. aeruginosa. Equal volumes of each parent were filtered onto a $0.45 \mu \mathrm{m}$ filter (Millipore). The filters were placed onto a $L B$ agar plate and incubated for 5-8 h before the filters were washed with $0.9^{\circ}$ s saline. Cells were plated on PIA selective plates supplemented with the appropriate antibiotic to determine the ability of the various region II constructs to complement various $\mathrm{Alg}^{-}$mutants. IPTG (isopropyl $\beta$-D-thiogalactopyranoside: final concentration $5 \mathrm{mM}$ ) was incorporated into agar plates to derepress the Ptac-lac $I^{4}$ system when required.

Maxicell analy'sis of alg gene products. Polypeptides synthesized from plasmid encoded genes were labelled by a modification of the E. coli maxicell technique described by Sancar $e t$ al. (1979). The E. coli maxicell strain CSR603 harbouring the relevant plasmid was grown to an $\mathrm{OD}_{6,0}$ of 0.5 in $\mathrm{M} 9$ minimal medium containing $0.6^{\circ}$ glucose, $1 \%$ Casamino acids and $5 \mu \mathrm{g}$ thiamin $\mathrm{ml}^{-1}$. After $\mathrm{UV}$ irradiation cycloserine was added to a final concentration of $200 \mu \mathrm{g} \mathrm{ml}^{-1}$ to kill those cells surviving the UV treatment. The cultures were then incubated for an additional $16 \mathrm{~h}$ at $37^{\circ} \mathrm{C}$ with aeration. Cells were collected by centrifugation and washed with Hershey's buffer (Worcel \& Burgi, 
Table 1. Bacterial strains and plasmids

\begin{tabular}{|c|c|c|}
\hline Strain/plasmid & Description & Reference \\
\hline \multicolumn{3}{|l|}{ E. coli } \\
\hline AC 80 & thr leu met hsdR hsdM & Chakrabarty et al. (1978) \\
\hline DHI & $\mathrm{F}^{-}$recAl end Al gyra96 thi-I & Low (1968) \\
\hline CSR603 & recA uvrA6 phr-l & Sancar et al. (1979) \\
\hline \multicolumn{3}{|l|}{ P. aeruginosa } \\
\hline 8821 & his-1 $\mathrm{Alg}^{+}$ & \\
\hline 8822 & his-1 alg-1 (spontaneous) & \\
\hline 8830 & his-1 $\mathrm{Alg}^{+}$(stable) & \\
\hline 8835 & his-l alg-5 & \\
\hline 8838 & his-I alg-8 & Darzıns \& Chakrabarty (1984) \\
\hline 8846 & his-1 alg-16 & \\
\hline 8857 & his-1 alg-27 & \\
\hline 8874 & his-1 alg-44 & \\
\hline 8887 & his- 1 alg- 60 & \\
\hline 8891 & his-I alg-67 & \\
\hline 8893 & his-1 alg-7I & Darzins et al. (1985b) \\
\hline 8897 & his-1 alg-76 & \\
\hline \multicolumn{3}{|l|}{ Plasmids } \\
\hline pCP13 & IncP $\mathrm{Tc}^{r} \mathrm{Km}^{r} \mathrm{Cos}^{+}$ & $\begin{array}{l}\text { Friedman et al. (1982); Darzins } \\
\text { \& Chakrabarty (1984) }\end{array}$ \\
\hline pKT240 & IncQ $K m^{r} A p^{r}$ & \\
\hline pMMB22 & IncQ Ap Prac lacIa & Bagdasarian et al. (1983) \\
\hline pMMB24 & IncQ Ap Ptac lac I $^{q}$ & \\
\hline $\mathrm{pKK} 223-3$ & ColE1 rep Ap Ptac & Amman et al. (1983) \\
\hline
\end{tabular}

1974) lacking sulphate. After $\mathrm{I}$ h of sulphate starvation the cells were suspended in Hershey's buffer containing $0.6 \%$ glucose and $1 \mathrm{~mm}$ each of proline, leucine, threonine and arginine. IPTG was added to a final concentration of $1 \mathrm{mM}$ when needed. [ ${ }^{35} \mathrm{~S}$ ]Methionine [Amersham; $\left.1250 \mathrm{Ci} \mathrm{mmol}^{-1}\left(46.25 \mathrm{TBq} \mathrm{mmol}{ }^{-1}\right)\right]$ was added to a final concentration of $5 \mu \mathrm{Ci} \mathrm{ml}^{-1}\left(185 \mathrm{kBq} \mathrm{ml} l^{-1}\right)$ and incubation was continued for another hour at $37^{\circ} \mathrm{C}$. The cells were washed twice with $100 \mathrm{~mm}$-potassium phosphate buffer, $\mathrm{pH} 7 \cdot 0$, resuspended in loading dye and the proteins were denatured by boiling at $100^{\circ} \mathrm{C}$ for $2 \mathrm{~min}$. Samples were subjected to SDS-PAGE as described by Dreyfuss $e t$ al. (1984). $\left[{ }^{35}\right.$ S]Methionine-labelled proteins were visualized by fluorography by using the water-soluble fluor sodium salicylate (Sigma) (Chamberlain, 1979).

Enzyme assays. The preparation of cell free extracts and the determination of PMM, GMP and GMD activities were done according to the methods described by Sa'-Correia et al. (1987). The protein concentration of the extracts was estimated according to the method of Bradford (1976). The protein assay reagent was obtained from Bio-Rad. Bovine serum albumin (BSA) was used as the protein standard. All phosphorylated sugars, nucleotides, sugar nucleotides and enzymes were obtained from Sigma.

\section{RESULTS}

Overexpression and size determination of alg gene products in the alg-8 and alg-44 region

Our laboratory has recently demonstrated that the activities of the four alginate biosynthetic enzymes - PMI, PMM, GMP and GMD - are normally present at low levels in mucoid $P$. aeruginosa cell free extracts (Sa'-Correia et al., 1987). The two genes for two alginate biosynthetic enzymes, namely pmi and gmd, have been characterized and sequenced only after the appropriate genes were cloned downstream of the trp-lac hybrid promoter (tac), so that hyperproduction after IPTG induction of the gene products allowed clear detection of the relevant enzymic activities (Darzins et al., 1986; Gill et al., 1986; Deretic et al., 1987a). These results indicated that the identification of each remaining alg gene function could ultimately depend on the ability to overproduce each gene product. The possible problem of low gene expression was, therefore, overcome by using plasmids which overexpressed alg functions from a strong promoter. 
The recombinant plasmid pAD2 has previously been shown to restore alginate producing capabilities to several alg mutants (Darzins \& Chakrabarty, 1984). The $9.5 \mathrm{~kb}$ HindIII fragment of pAD2, which resides within region II, was subcloned into the tac promoter-containing broad host range expression vector pMMB24. The resulting plasmids, pSK402 (Fig. $1 b$ ) and pSK 40I, contained the tac promoter at opposite ends of the pAD2 HindIII fragment. In the absence of IPTG, plasmids pSK 402 and pSK 401 were able to complement only those mutants previously shown to be complemented by pAD2 and no additional alg mutants were complemented upon IPTG induction. The DNA fragment of a subclone of pAD2 (designated pSK 2005, Fig. $1 b$ ), which complemented only one of these alg mutants (alg-5), is located most distal from the phosphomannose isomerase gene $(\operatorname{alg} A)$ nearest the $\arg F$ gene on the $P$. aeruginosa chromosome (Darzins et al., 1985a). Further subcloning of an internal $2.7 \mathrm{~kb} \mathrm{ClaI-}$ $X m a I$ fragment of the DNA insert of pSK 2005 resulted in the construction of plasmid pSK 123 which placed the $t a c$ promoter next to the $C l a I$ site (Fig. 1 b). Plasmid pSK 123 was able to restore alg-5 to $\mathrm{Alg}^{+}$but only in the presence of IPTG. An analogous plasmid construct which placed the $t a c$ promoter adjacent to the XmaI site was unable to complement alg-5 even in the presence of IPTG. These results suggest that the promoter of the alg-5 complementing gene may reside upstream of the ClaI site and that the transcriptional orientation of alg-5 is from the ClaI site toward the $X m a I$ site. These observations are in agreement with the direction of transcription and sequence analysis of this fragment which has recently been shown to contain the gene ( $g m d$ ) encoding GDP-mannose dehydrogenase (Deretic et al., 1987a).

Located immediately downstream of gmd are two distinct alginate loci, alg-8 and alg-44. Plasmid pSK 2001 , which contains a $4.2 \mathrm{~kb}$ XhoI-Pst I fragment of pSK 402 , complements alg -8 (Darzins et al., 1985b). The $4 \cdot 2 \mathrm{~kb}$ fragment of pSK2001 was subcloned into pMMB24 and the resulting plasmids, designated pSK2021 (Fig. $1 b$ ) and pSK2022 (not shown), placed the tac promoter adjacent to the XhoI and PstI sites, respectively. Plasmid pSK2021 was capable of complementing alg- 8 only upon IPTG induction of the tac promoter while pSK 2022 failed to restore alginate production in the same mutant even upon IPTG induction. Furthermore, pSK 2021 was also capable of complementing alg-44 upon IPTG induction. Plasmid pAD5059 (Fig. $1 b$ ), which shares common region II sequences with pSK2021, complements only alg-44 upon IPTG induction (Darzins et al., 1985b). An additional plasmid that further localized the alg.44 complementation function was constructed. A $1.9 \mathrm{~kb} \mathrm{BglII}-P$ st I fragment of the $4.2 \mathrm{~kb}$ Xhol-Pst I fragment of pSK2021 was subcloned into the tac containing, broad host range expression vector, pMMB22. The resulting construct, designated pSK311 (Fig. $1 b$ ), contained the tac promoter adjacent to the $B g / I I$ site and was capable of complementing alg-44 to $\mathrm{Alg}^{+}$ upon IPTG induction. These results, therefore, demonstrate that both alg-8 and alg-44 reside within the $4.2 \mathrm{~kb}$ XhoI-Pst I fragment of pSK2021 and further suggest that the direction of transcription of these two alg loci is in the same direction as that found for alg-5 ( $\mathrm{gmd}$ ).

The plasmid-encoded gene products of the $a l g-8$ and $a l g-44$ region were examined in the $E$. coli plasmid maxicell system and labelled with $\left[{ }^{35}\right.$ S $]$ methionine. We were unable, however, to detect the synthesis of any unique, non-vector polypeptides encoded by plasmids pSK2021 and pSK 311. Similarly, plasmid pAD5059 is only able to direct the synthesis of a faint $51 \mathrm{kDa}$ polypeptide (data not shown). In an attempt to better visualize the alg gene products the DNA fragments of pSK2021, pSK 311 and pAD5059 were recloned into the ColE1 based, high copy number, constitutive expression (tac) vector pKK223-3. This resulted in the construction of plasmids pSK2023, pSK 315 and pSK 341, respectively (Fig. $1 b$ ). When compared to pKK223-3 encoded proteins (Fig. 2, lane A), pSK2023 directed the synthesis of a unique $41 \mathrm{kDa}$ polypeptide (Fig. 2, lane B). pSK 315 , which contains sequences capable of complementing alg44, directed the synthesis of two consistently reproducible new polypeptides with apparent molecular masses of 41 and $15 \mathrm{kDa}$ (Fig. 2, lane C). The other small molecular mass proteins (Fig. 2), however, did not migrate in a consistent manner from one experiment to the next and are believed to represent degraded fragments of the existing polypeptides. DNA sequence analysis of a $1.5 \mathrm{~kb} \mathrm{Bg} / \mathrm{II}-K p n I$ DNA fragment contained within the $1.9 \mathrm{~kb} \mathrm{BglII}-P s t$ I fragment of pSK 315 revealed an open reading frame capable of coding for a $40.6 \mathrm{kDa}$ protein (S.-K. Wang, unpublished data). An additional open reading frame coding for a $14 \mathrm{kDa}$ protein was 


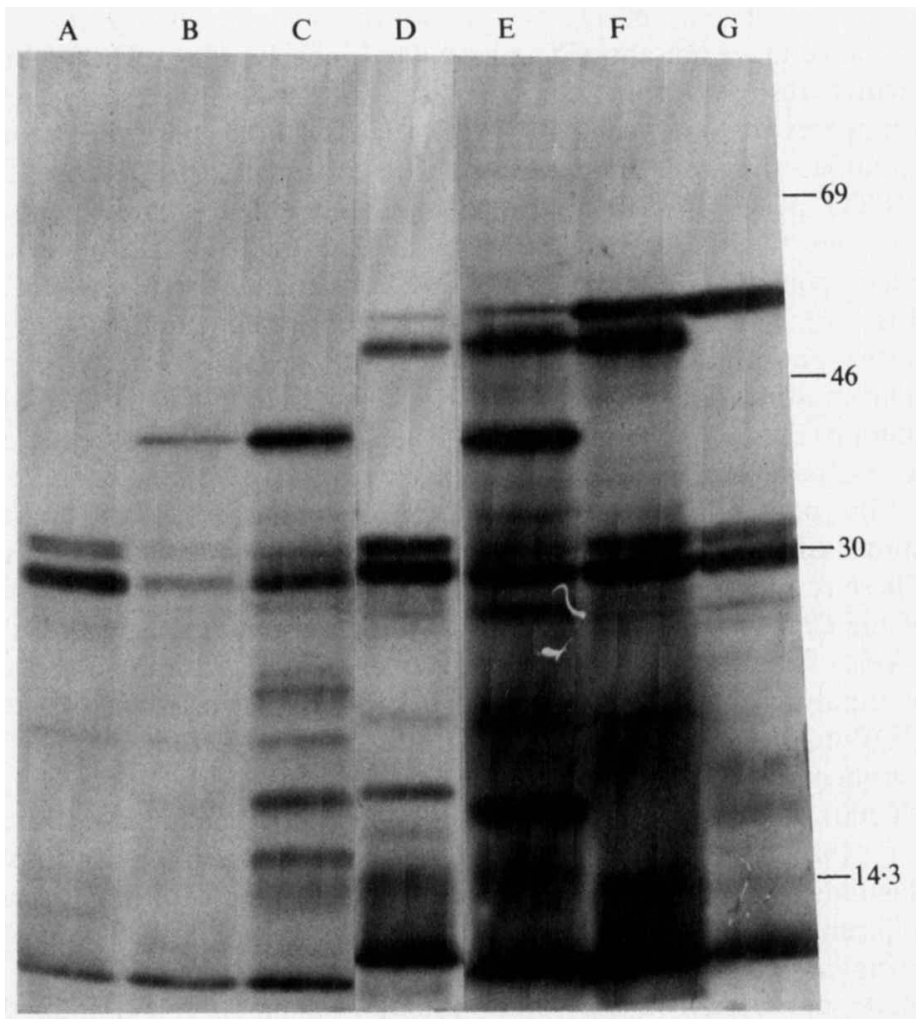

Fig. 2. SDS-PAGE of proteins synthesized and labelled in maxicells. Autoradiogram of plasmidencoded polypeptides. Lanes: A, pKK223-3; B, pSK 2023; C, pSK 315; D, pSK 434; E, pSK341; F, pSK 430; G, pSK 530. Molecular mass marker proteins (kDa) are indicated at the right.

also found to overlap with that of the larger open reading frame. In order to examine the possible function of the $14 \mathrm{kDa}$ polypeptide, plasmid pSK331 was constructed (Fig. 1b). pSK331 was obtained by cloning the $0.98 \mathrm{~kb}$ Sal I-KpnI fragment of pSK315 into pMMB24 with the SalI site adjacent to the $t a c$ promoter. This plasmid retained the entire $14 \mathrm{kDa}$ open reading frame but remained unable to complement alg-44. This result demonstrates that it is the $41 \mathrm{kDa}$ protein and not the $14 \mathrm{kDa}$ polypeptide synthesized by pSK 315 that most likely is the alg-44 gene product. Protein hydrophobicity analysis of the alg-44 gene product demonstrated the presence of three hydrophobic domains (S.-K. Wang, unpublished data). In addition, the Nterminal sequence of the polypeptide does not show any homology with $E$. coli signal peptides suggesting that the alg-44 gene product may indeed be a membrane bound protein. However, further subcloning and overexpression studies of specifically that portion of pSK2023 responsible for alg-8 complementation will be needed for a more definitive gene product assignment.

pSK 341 , which contains both pSK 315 and downstream sequences, was found to direct the synthesis of two additional polypeptides with apparent molecular masses of 51 and $54 \mathrm{kDa}$ (Fig. 2 , lane E). This result suggested the possible existence of additional coding sequences downstream of the alg-44 locus. The analysis of plasmid pSK434 (Fig. $1 b$ ), which contained the $1.8 \mathrm{~kb} X \mathrm{mal}-E c o \mathrm{RI}$ fragment of pSK 341 and was therefore devoid of alg-44 coding sequences, supported this conclusion. This plasmid also encoded two polypeptides with apparent molecular masses of 51 and $54 \mathrm{kDa}$ (Fig. 2, lane D). 


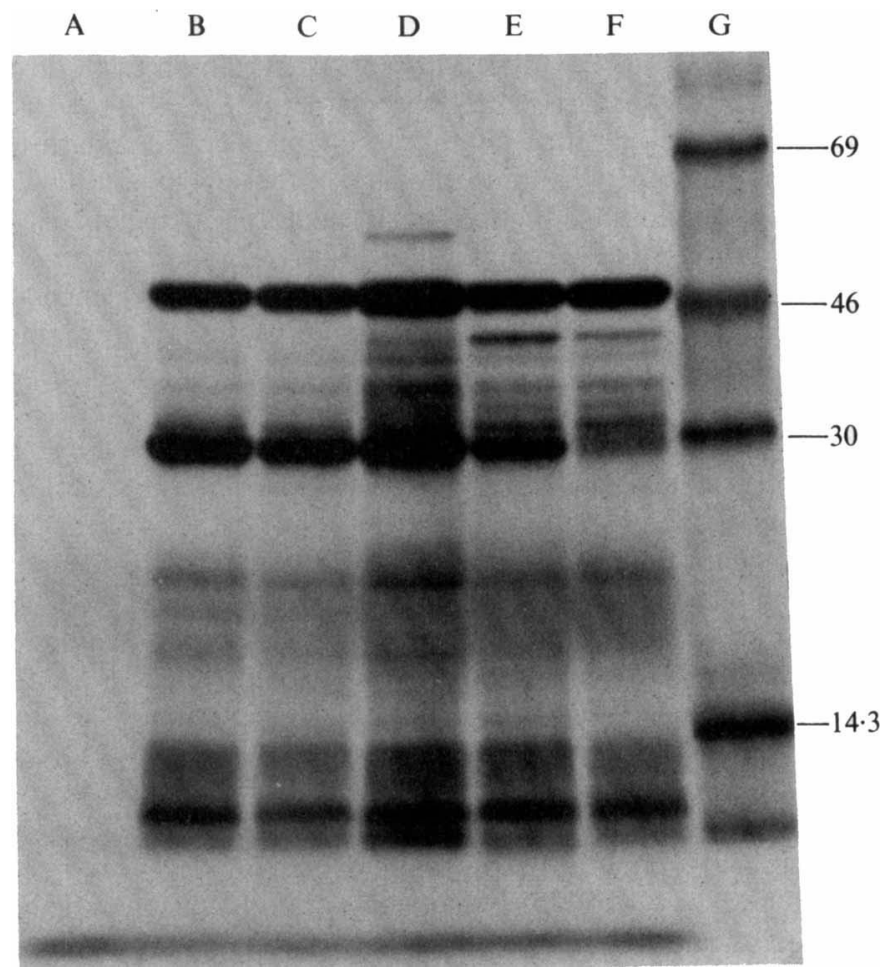

Fig. 3. SDS-PAGE of proteins synthesized and labelled in maxicells. Autoradiogram of plasmidencoded polypeptides. Lanes: A, no plasmid; B, pMMB22; C, pMMB24; D, pISC10; E, pSK 700; F, pAD4047; $\mathrm{G}$, labelled molecular mass marker proteins (kDa).

\section{Overexpression and size determination of alg gene products in the alg-76 region}

Previous cloning and complementation studies have tentatively localized the alg-76 complementing activity downstream of the alg-44 locus (Darzins et al., 1985b). Plasmid pSK 431 (Fig. $1 b$ ) contains a $3.8 \mathrm{~kb} \mathrm{Xmal-HindIII} \mathrm{fragment} \mathrm{from} \mathrm{near} \mathrm{the} \mathrm{centre} \mathrm{of} \mathrm{the} \mathrm{region} \mathrm{II} \mathrm{alg}$ cluster and was capable of restoring alginate producing capabilities to $a l g-76$. The $3.8 \mathrm{~kb}$ fragment of pSK431 was cloned into the expression vector pKK223-3 so as to place the tac promoter next to the XmaI site and the resulting plasmid was designated pSK430. A maxicell analysis of this plasmid revealed the synthesis of two unique polypeptides with apparent molecular masses of 51 and $54 \mathrm{kDa}$ (Fig. 2, lane F). This result pointed out the possibility that two coding regions may be contained within the $3.8 \mathrm{~kb} \mathrm{XmaI-HindIII} \mathrm{fragment} \mathrm{of} \mathrm{pSK430.} \mathrm{In}$ order to identify which of these polypeptides could correspond to the alg-76 gene product, plasmid pSK 530 was constructed. The $3.8 \mathrm{~kb}$ fragment of pSK431 was isolated, digested with $B g / \mathrm{II}$ and the $2.4 \mathrm{~kb} \mathrm{Bg} / \mathrm{II}-$ HindIII fragment was cloned into both pCP13 and pKK223-3 resulting in the construction of pAD318 and pSK530, respectively (Fig. $1 b$ ). pAD318 was capable of complementing alg-76 to $\mathrm{Alg}^{+}$and pSK 530 directed the synthesis of a protein with an apparent molecular mass of $54 \mathrm{kDa}$ (Fig. 2, lane G). These results first suggest that the gene product for alg-76 is a $54 \mathrm{kDa}$ protein and second, that an additional coding sequence lies between the alg-44 and alg-76 loci.

Overexpression and size determination of alg gene products in the alg-60 region

Work from this laboratory has previously demonstrated that the alg- 60 structural gene resides within a $3.2 \mathrm{~kb}$ XhoI-HindIII fragment located downstream of the alg-76 locus (Darzins et al., $1985 b$ ). A $3.4 \mathrm{~kb} \mathrm{XbaI-HindIII} \mathrm{fragment} \mathrm{containing} \mathrm{the} \mathrm{entire} 3.2 \mathrm{~kb}$ alg-60 complementing 
sequence was cloned into the broad host range expression vector pMMB24 and the resulting plasmid was designated pISC10 (Fig. $1 b$ ). This construct, which contained the tac promoter adjacent to the HindIII site, was capable of complementing alg-60 to $\mathrm{Alg}^{+}$. Compared with pMMB24, pISC 10 encoded two additional faint protein bands which migrated at 55 and $43 \mathrm{kDa}$ (Fig. 3, lanes $C$ and D). In order to distinguish which of these polypeptides could correspond to the alg-60 gene product plasmid pSK 700 was constructed. A $1.8 \mathrm{~kb}$ XbaI-EcoRI fragment from the $3.4 \mathrm{~kb}$ fragment of pISC10 was subcloned into pMMB22 placing the tac promoter adjacent to the $E c o$ RI site (Fig. 1 b). The resulting plasmid, designated pSK 700 , encoded a unique $43 \mathrm{kDa}$ protein (Fig. 3, lane E). Plasmid pAD4047, which contains the DNA fragment of pSK 700 and those contiguous sequences up to and including the pmi gene (Darzins et al., 1986; Fig. 1 b), also directed the synthesis of the $43 \mathrm{kDa}$ polypeptide (Fig. 3, lane F). Since both pSK 700 and pAD4047 failed to complement alg-60 the $55 \mathrm{kDa}$ protein synthesized by pISC10 is a possible candidate for the alg- 60 gene product. Inactivation of alg- 60 by some sort of insertion or deletion with a concomitant loss of complementing ability and the synthesis of the $55 \mathrm{kDa}$ polypeptide, however, will be required for final confirmation. The $43 \mathrm{kDa}$ polypeptide most likely represents another coding sequence located downstream of alg- 60 .

The remaining $3.6 \mathrm{~kb}$ of DNA between the $43 \mathrm{kDa}$ coding region and the pmi gene represented by the recombinant plasmid pSK810 (Fig. $1 b$ ) failed to produce any detectable polypeptides in maxicell studies (data not shown). However, pSK810 and pSK700 had a profound effect on the alginate producing capability of strain 8821. Cells of strain 8821 harbouring these plasmids grew slowly and became phenotypically non-mucoid when grown on agar plates containing carbenicillin in the presence of IPTG. Restreaking of the non-mucoid colonies onto fresh agar plates containing antibiotic but lacking IPTG resulted in the restoration of the mucoid phenotype. The control transconjugants obtained using only the expression vector used to construct pSK 700 and pSK810 were not prevented from producing exopolysaccharide. These results suggest that even though no polypeptides were detected in the maxicell analysis of pSK810, some gene(s) exist within the cloned fragment of pSK810 whose product(s), when present in excess, interfere with growth and polysaccharide production.

\section{Quantification of alginate biosynthetic enzymes}

Since assays for detecting low levels of PMI, PMM, GMP and GMD in P. aeruginosa have recently been described (Sa'-Correia et al., 1987) we attempted to further characterize the four alg loci (alg-60, alg-76, alg-44 and alg-8), their possible corresponding complementing gene products and the two additional coding sequences located within alg region II downstream of the alg-44 and alg-60 loci. Even though the gmd gene has just recently been identified, specific activities of PMM, GMP and GMD were determined in the four alg mutants and in a mucoid and non-mucoid strain harbouring appropriate region II overproducing constructs.

Table 2 shows that all four mutants contained PMM, GMP and GMD levels that were similar to those values obtained for either the stable mucoid parent strain 8830 or the unstable mucoid strain 8821 . The only exceptions were $a l g-8$ and $a l g-44$ which had levels of GMD that were consistently lower than the value for 8830 . The non-mucoid phenotype of these two mutants, however, could not be attributed to the lower activities of GMD for the following reason. Plasmid pSK 311 was able to restore alginate producing capabilities to alg-44. The GMD level of alg-44 harbouring pSK 311 , however, was not significantly different from the value of GMD obtained with alg-44 alone (Table 2). In addition, overexpression of pSK 311 by IPTG induction did not induce significant changes in the specific activity of GMD. Similar results were obtained with plasmid pSK2021, the recombinant plasmid capable of complementing alg-8 (data not shown).

In order to ascertain the effect of overproducing various region II protein products on the level of the alginate biosynthetic enzymes the following region II constructs were introduced into the mucoid 8821 strain and a spontaneous non-mucoid revertant strain (8822): pSK 402 for any additional alg loci which may reside upstream of alg-5, pSK 123 for alg-5, pSK 2021 for alg-8 and alg-44, pSK 311 for alg-44, pAD5059 for alg-44 and the $51 \mathrm{kDa}$ coding sequence, pSK 431, for the $51 \mathrm{kDa}$ coding sequence and $a l g-76$, pISC 10 for alg- 60 and the $43 \mathrm{kDa}$ coding sequence and 


\section{Table 2. Specific activities of PMM, GMP and GMD in mucoid and non-mucoid $P$. aeruginosa strains}

$1 \mathrm{mU}$ is defined as the formation of $1 \mathrm{nmol} \mathrm{NADPH}$ or NADH $\mathrm{min}^{-1}$.

\begin{tabular}{|c|c|c|c|c|}
\hline Strain/plasmid & Phenotype & \multicolumn{3}{|c|}{$\left[\mathrm{mU}(\mathrm{mg} \text { protein })^{-1}\right]$} \\
\hline 8821 & Mucoid & $2 \cdot 0$ & 1.2 & 8.0 \\
\hline 8830 & Mucoid & 1.6 & $2 \cdot 3$ & 10.6 \\
\hline $8838($ alg- 8$)$ & Non-mucoid & 1.5 & 2.5 & $2 \cdot 5$ \\
\hline $8874($ alg-44) & Non-mucoid & 1.5 & 2.4 & $3 \cdot 7$ \\
\hline 8897 (alg-76) & Non-mucoid & 1.0 & $1 \cdot 2$ & $8 \cdot 1$ \\
\hline 8887 (alg-60) & Non-mucoid & 0.8 & 0.9 & 9.6 \\
\hline 8874/pSK 311 & Mucoid & 1.4 & $2 \cdot 1$ & $3 \cdot 2$ \\
\hline $8874 /$ pSK $311^{*}$ & Mucoid & 1.2 & $2 \cdot 1$ & \\
\hline
\end{tabular}

* IPTG added to $5 \mathrm{~mm}$ (final concentration).

pSK 700 for the $43 \mathrm{kDa}$ coding sequence. Plasmids pSK2021, pSK311, pAD5059, pSK 431 and pISC10 failed to have any effect on either PMM, GMP, or GMD activities in either 8821 or 8822 upon IPTG induction (data not shown). The non-mucoid strain 8822 harbouring plasmid pSK 123 showed a dramatic increase in GMD activity $[68 \mathrm{mU} \text { (mg protein })^{-1}$ compared to $9 \mathrm{mU}$ (mg protein) ${ }^{-1}$ without IPTG induction]. This is consistent with the finding that pSK 123 harbours the structural gene for GMD. The only other region II construct which had any effect on the alginate biosynthetic enzyme activities was pSK 700. Strain 8822 harbouring pSK 700 was found to have a reproducible $3 \cdot 5$-fold increase in the GMD activity from $2 \mathrm{mU}(\mathrm{mg} \text { protein })^{-1}$ to $7 \mathrm{mU}(\mathrm{mg} \text { protein })^{-1}$ upon IPTG induction.

\section{DISCUSSION}

In this study, the $P$. aeruginosa alginate biosynthetic gene cluster, designated region II, was further characterized. Gene expression studies with several region II constructs revealed that the transcriptional orientation of the known alg loci was unidirectional, with transcription proceeding from gmd (located proximal to $\arg F$ ) to pmi (Fig. $1 b$ ). Two additional, possibly alg related, polypeptides were encoded from within the alg gene cluster and the genes encoding these additional proteins appeared to be also transcribed in the same orientation as the other alg genes within region II.

One of these additional polypeptides was coded for by a $1.8 \mathrm{~kb} \mathrm{XmaI-EcoRI} \mathrm{fragment} \mathrm{located}$ between alg-44 and alg-76. Plasmids pSK434 and pAD5059 consistently produced two polypeptides, 54 and $51 \mathrm{kDa}$ in size. Since $1 \mathrm{~kb}$ of DNA can (roughly) code for a $37 \mathrm{kDa}$ polypeptide it seems unlikely that the $1.8 \mathrm{~kb}$ DNA fragment of pSK 434 could harbour two nonoverlapping genes coding for a 54 and a $51 \mathrm{kDa}$ protein. A possible explanation for this result is that these two polypeptides share the same open reading frame but initiate translation at different points along the open reading frame. Another possibility is that the $54 \mathrm{kDa}$ polypeptide may be the precursor form of the $51 \mathrm{kDa}$ polypeptide which was formed by a posttranslational modification (i.e., cleavage of a small peptide). As of yet, no alg mutants have been isolated which map to this locus. However, we believe that since the DNA fragment encoding this polypeptide is flanked by two alg loci involved in alginate biosynthesis (alg-44 and $a l g-76)$ it is likely that this polypeptide is also involved in the production of alginic acid.

The second additional polypeptide $(43 \mathrm{kDa})$ was found to be encoded by DNA sequences immediately downstream of alg-60. Overproduction of the $43 \mathrm{kDa}$ protein by plasmid pSK 700 in 8822 resulted in the 3 -fold increase of GMD activity to near wild-type mucoid levels suggesting that this polypeptide may act as an activator for GMD expression. Overexpression of pSK 700 did not have an effect in the mucoid 8821 strain as no further increases in GMD activity were detected. Even though chemical induced mutants defective in alginate biosynthesis have 
not been isolated in this locus, we believe that the following justification is reason enough to consider that this region may also be involved in exopolysaccharide production.

Several smaller segments of the $3.6 \mathrm{~kb}$ fragment between the $43 \mathrm{kDa}$ coding region and the pmi gene have been cloned into the ColEl based, narrow host range vector, pBR325. These plasmids cannot replicate autonomously in $P$. aeruginosa and their maintenance within $P$. aeruginosa is solely dependent on their ability to integrate into the chromosome by recombination at the site of homology (Darzins et al., 1985b). The integration of these constructs into the chromosome of the mucoid strain 8830 resulted in tetracycline resistant transconjugants which had lost the mucoid phenotype (data not shown). This result indicates that the plasmid insertions either disrupted crucial genes involved in alginate biosynthesis or interrupted the normal process of transcription through this region. This is consistent with the recent report that the pmi gene may be part of a single regulatory unit which has at its $5^{\prime}$ end the $43 \mathrm{kDa}$ coding region (Darzins et al., 1986). Our laboratory has recently shown that the overproduction of PMI causes the derepression of PMM and GMP activity but not of GMD (Sa'-Correia et al., 1987). Since the presence of GMD activity is indispensable for alginate production it is important to derepress GMD activity also. It is thus likely that the $43 \mathrm{kDa}$ polypeptide plays a role in the derepression of the GMD activity.

The ability of a cloned DNA fragment to inhibit exopolysaccharide synthesis in other bacterial systems has previously been reported. In $E$. coli the biosynthesis of capsular polysaccharide (colanic acid) is negatively regulated by the lon gene product which is in turn positively regulated by the $O m p T$ gene. The product of the $O m p T$ gene is a $40 \mathrm{kDa}$ major outer membrane protein known as $a$ (also known as $3 \mathrm{~b}$ or M2) (Gayda et al., 1979). Overproduction of the $O m p T$ gene product has led to the repression of colanic acid synthesis (Berg et al., 1976; Gayda et al., 1979). Similarly, wild-type Rhizobium strains produce an exopolysaccharide thought to be involved in the symbiotic relationship between plant and bacterium. A region of the symbiotic plasmid pRP2JI when cloned at an increased copy number inhibited exopolysaccharide synthesis (Borthakur et al., 1985). It has been proposed that the psi (polysaccharide inhibition) gene is a regulatory gene that acts to repress the expression of gene(s) involved in exopolysaccharide synthesis in the plant associated bacteroid. It is possible that the products from pSK 700 and pSK 810 responsible for inhibiting alginate production could be somehow negatively regulating exopolysaccharide synthesis or could be sterically interfering with the polymerization and/or secretion processes. $P$. aeruginosa, in addition to producing a very viscous exopolysaccharide, also produces an enzyme (alginase) capable of degrading this polymer. Alginase activity is believed to be responsible for the loss in viscosity of alginate during later stages of cell growth (Linker \& Evans, 1984). However, the genetic aspects of alginase production remain unclear.

Except for the pmi and gmd genes the functions of the remaining genes in region II are still not fully understood. One thing that becomes clear, however, is that the remaining genes do not appear to encode either PMM or GMP activities. This conclusion is supported by the finding that all of the alg mutants mapped to region II contained wild-type levels of PMM and GMP and that overproduction of region II gene products (excluding PMI) failed to demonstrate increased levels of these two enzymes. The results of this study strongly point to the fact that the remaining genes present within region II may be involved in the conversion of GDP-mannuronic acid to alginate, catalysing such steps as polymerization of mannuronic acid residues and secretion, epimerization and acetylation of the resulting polymer.

This investigation was supported by Public Health Service Grant AI 16790-08 from the National Institute of Allergy and Infectious Diseases and in part by the Earl M. Bane Charitable Trust administered by the University of Illinois at Chicago. Isabel Sa'-Correia was supported by a fellowship from the Gulbenkian Foundation.

\section{REFERENCES}

Amman, E., Brosius, J. \& Ptashne, M. (1983). Vector bearing a hybrid trp-lac promoter useful for regulated expression of cloned genes in Escherichia coli. Gene 25, 167-178.

Bagdasarian, M. M., Amman, E., LuRz, R., Ruc-
KERT, B. \& BAGDASARIAN, M. (1983). Activity of the hybrid trp-lac (tac) promoter of Escherichia coli in Pseudomonas putida. Construction of broad-host range, controlled expression vectors. Gene 26, 273282. 
Berg, P. E., Gayda, R., Avnı, H., Zehnbauer, B. \& MARKovitz, A. (1976). Cloning of Escherichia coli DNA that controls cell division and capsular polysaccharide synthesis. Proceedings of the National Academy of Sciences of the United States of America 73, 697-701.

BorthakuR, D., Downie, J. A., Johnston, A. W. B. \& LAMB, J. W. (1985). psi, a plasmid-linked Rhizobium phaseoli gene that inhibits exopolysaccharide production and which is required for symbiotic nitrogen fixation. Molecular and General Genetics 200, 278282.

BRADFORD, M. (1976). A rapid and sensitive method for the quantitation of microgram quantities of protein utilizing the principle of protein-dye binding. Analytical Biochemistry 72, 248-254.

Casse, F., Boucher, C., Julliot, J. S., Michel, M. \& DENARIE, H. (1979). Identification and characterization of large plasmids in Rhizobium meliloti using agarose gel electrophoresis. Journal of General Microbiolog! 113, 229-242.

Chakrabarty, A. M., Friello, D. A. \& Bopp, L. H. (1978). Transposition of plasmid DNA segments specifying hydrocarbon degradation and their expression in various microorganisms. Proceedings of the National Academy of Sciences of the United States of America 75, 3109-3112.

Chamberlain, J. P. (1979). Fluorographic detection of radioactivity in polyacylamide gels with the water soluble fluor, sodium salicylate. Analytical Biochemistry 98, 132-135.

Chatterjee, D. K., Kellog, S. T., Hamada, S. \& Chakrabarty, A. M. (1981). Plasmid specifying total degradation of 3-chlorobenzoate by a modified ortho pathway. Journal of Bacteriology 146, 639-646.

Darzins, A. \& Chakrabarty, A. M. (1984). Cloning of genes controlling alginate biosynthesis from a mucoid cystic fibrosis isolate of Pseudomonas aeruginosa. Journal of Bacteriology' 159, 9-18.

Darzins, A.. NiXon, L. L., Vanags, R. I. \& Chakrabarty, A. M. (1985a). Cloning of Escherichia coli and Pseudomonas aeruginosa phosphomannose isomerase genes and their expression in alginate-negative mutants of Pseudomonas aeruginosa. Journal of Bacteriology 161, 249-257.

Darzins, A., Wang, S.-K., Vanags, R. I. \& ChakraBARTY, A. M. $(1985 b)$. Clustering of mutations affecting alginic acid biosynthesis in mucoid Pseudomonas aeruginosa. Journal of Bacteriolog. 164, 516524.

Darzins, A., Frantz, B., Vanags, R. I. \& ChakraBARTY, A. M. (1986). Nucleotide sequence analysis of the phosphomannose isomerase gene $(\mathrm{pmi})$ of Pseudomonas aeruginosa and comparison with the corresponding Escherichia coli gene manA. Gene 42, 293-302.

Deretic, V., Tomasek, P., Darzins, A. \& ChakraBARTY, A. M. (1986). Gene amplification induces mucoid phenotype in rec-2 Pseudomonas aeruginosa exposed to kanamycin. Journal of Bacteriology 165. $510-516$.

Deretic, V., Gill, J. F. \& Chakrabarty, A. M. $(1987 a)$. Gene alg $D$ coding for GDP-mannose dehydrogenase is transcriptionally activated in mucoid Pseudomonas aeruginosa. Journal of Bacteriology 169, 351-358.
Deretic, V., Gill, J. F. \& Chakrabarty, A. M. $(1987 \mathrm{~b})$. Alginate biosynthesis: a model system for gene regulation and function in Pseudomonas. Bio/ Technology 5, 469-477.

DoggetT, R. G. (1979). Incidence of mucoid Pseudomonas aeruginosa from clinical sources. Applied Microbiology 18, 936-937.

Doggett, R. G., Harrison, G. M. \& Carter, R. E. (1971). Mucoid Pseudomonas aeruginosa in patients with chronic illness. Lancet i, 236-237.

Dreyfuss, G., AdaM, S. A. \& ChOI, Y. D. (1984). Physical change in cytoplasmic messenger ribonucleoproteins in cells treated with inhibitor of mRNA transcription. Molecular and Cellular Biology 4, 415423.

Drummond, D. W., Hirst, E. L. \& Persival, E. F. (1962). The constitution of alginic acid. Journal of the Chemical Society 2, 1208-1216.

Evans, L. R. \& Linker, A. (1973). Production and characterization of the slime polysaccharide of Pseudomonas aeruginosa. Journal of Bacteriology 116, 915-924.

Figurski, D. \& Helinski, D. (1979). Replication of an origin-containing derivative of plasmid RK2 dependent on a plasmid function provided in trans. Proceedings of the National Academy of Sciences of the United States of America 76, 1648-1652.

Friedman, A. M., LoNG, S. R., Brown, S. E., Buikema, W. J. \& Ausubel, F. M. (1982). Construction of a broad host range cosmid cloning vector and its use in the genetic analysis of Rhizobium mutants. Gene 18, 289-296.

Gayda, R., Avni, H., Berg, P. E. \& Markovitz, A. (1979). Outer membrane protein $a$ and other polypeptides regulate capsular polysaccharide synthesis in E. coli K-12. Molecular and General Genetics 175, 325-332.

Gill, J. F., Deretic, V. \& Chakrabarty, A. M. (1986). Overproduction and assay of Pseudomonas aeruginosa phosphomannose isomerase. Journal of Bacteriology 167, 611-615.

Gorin, P. A. J. \& SPENCER, J. F. T. (1966). Exocellular alginic acid from Azotobacter vinelandii. Canadian Journal of Chemistry 44, 993-998.

Iacocca, V. F., Sibinga, M. S. \& Barbero, G. J. (1963). Respiratory tract bacteriology in cystic fibrosis. American Journal of the Diseases of Children 106, 315-324.

LIN, T.-Y. \& HASsid, W. Z. (1966). Pathway of alginic acid synthesis in the marine brown alga, Fucus gardneri Silva. Journal of Biological Chemistry 241, 5284-5297.

LINKER, A. \& EVANS, L. R. (1984). Isolation and characterization of an alginase from mucoid strains of Pseudomonas aeruginosa. Journal of Bacteriology 159, 958--964.

LINKER, A. \& JONES, R. S. (1966). A new polysaccharide resembling alginic acid isolated from pseudomonads. Journal of Biological Chemistry 241, 38453851 .

Low, B. (1968). Formation of merodiploids in matings with a class of Rec recipient strains of Escherichia coli K-12. Proceedings of the National Academy of Sciences of the United States of America 60, 160-167.

Maniatis, T., Fritsch, E. F. \& Sambrook, J. (1982). 
Molecular Cloning. Cold Spring Harbor, New York: Cold Spring Harbor Laboratory.

Mian, F. A., Jarman, T. R. \& Righelato, R. C. (1978). Biosynthesis of exopolysaccharide by Pseudomonas aeruginosa. Journal of Bacteriology 134, 418422.

Miller, J. H. (1972). Experiments in Molecular Genetics. Cold Spring Harbor, New York: Cold Spring Harbor Laboratory.

Piggott, N. H., Sutherland, I. W. \& Jarman, T. R. (1981). Enzymes involved in the biosynthesis of alginate by Pseudomonas aeruginosa. European Journal of Applied Microbiology and Biotechnology 13, 179-183.

Sa'-Correia, I., Darzins, A., Wang, S.-K., Berry, A. \& ChaKrabarTY, A. M. (1987). Alginate biosynthe- tic enzymes in mucoid and non-mucoid Pseudomonas aeruginosa: overproduction of phosphomannose isomerase, phosphomannose mutase and GDP-mannose pyrophosphorylase by overexpression of the phosphomannose isomerase (pmi) gene. Journal of Bacteriology (in the Press).

SANCAR, A., HaCk, A. M. \& RupP, W. D. (1979). Simple method for identification of plasmid encoded proteins. Journal of Bacteriology 137, 692-693.

SUTHERLAND, I. W. (1982). Biosynthesis of microbial exopolysaccharides. Advances in Microbial Physiology 23, 79-150.

Worcel, A. \& Burgi, E. (1974). Properties of a membrane-attached form of the folded chromosome of Escherichia coli. Journal of Molecular Biology 82, 91-105. 